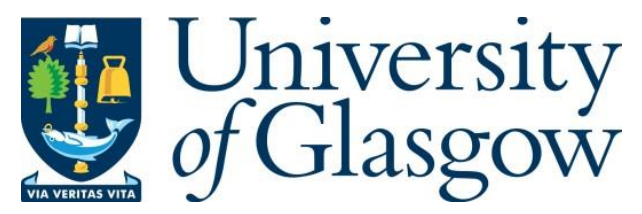

Ciobanu, R. O. and Hunter, A. (2017) Older migrants and (im)mobilities of ageing: an introduction. Population, Space and Place, 23(5), e2075.

There may be differences between this version and the published version. You are advised to consult the publisher's version if you wish to cite from it.

This is the peer reviewed version of the following article Ciobanu, R. O. and Hunter, A. (2017) Older migrants and (im)mobilities of ageing: an introduction. Population, Space and Place, 23(5), e2075, which has been published in final form at http://dx.doi.org/10.1002/psp.2075. This article may be used for non-commercial purposes in accordance with Wiley Terms and Conditions for Self-Archiving.

http://eprints.gla.ac.uk/178718/

Deposited on: 29 January 2019

Enlighten - Research publications by members of the University of Glasgow http://eprints.gla.ac.uk 


\title{
Older migrants and (im)mobilities of ageing: an introduction
}

\section{Ruxandra Oana Ciobanu and Alistair Hunter}

Ruxandra Oana Ciobanu (corresponding author)

Center for the Interdisciplinary Study of Gerontology and Vulnerability

University of Geneva

Swiss National Centre of Competences in Research LIVES

54 rte des Acacias

1227 Carouge (GE), Switzerland

Tel.: +41 (0)223793791

E-mail: oana.ciobanu@unige.ch

\author{
Alistair Hunter \\ The Alwaleed Centre \\ University of Edinburgh \\ 19 George Square \\ Edinburgh EH8 9LD \\ United Kingdom
}

Tel.: +44 (0)131 6504324

E-mail: alistair.hunter@ed.ac.uk

\begin{abstract}
This guest editorial introduces a special issue entitled 'Older migrants: (im)mobilities of ageing'. The movement of people is a core concern of population geographers and the last decade has witnessed a 'mobilities turn'. This literature has given much attention to younger people who move, but thus far has largely ignored people who migrate in later life, or whose previous migrations significantly shape their present experiences of ageing. The articles in this special issue address this lacuna, drawing on different categories of older international migrants to and from various European countries. More specifically, the special issue's ambition is to respond to two questions. What added value does the 'new mobilities paradigm' contribute to the study of older migrants, who may have migrated long ago or be less mobile today than in the past? And conversely, what added value does studying older migrants contribute to the mobilities paradigm? While acknowledging earlier critiques of this paradigm, we contend that
\end{abstract}


the mobilities perspective helps to elucidate the experiences of older migrants, through its insistence on the capacity for mobility - whether physical, virtual, communicative, imaginative - at diverse scales, including but certainly not limited to international cross-border moves. Mobility thus conceived is an important but neglected factor for older people to achieve better quality of life. We also argue that research with older migrants offers rich potential for refining the mobilities paradigm, for example in terms of 'mobility regimes' governing access to healthcare and social protection, to which older migrants may be particularly exposed.

Key words: older migrants, mobility, immobility, old age, migration, transnationalism 
The idea for this special issue was born at the 2012 annual conference of the IMISCOE research network (International Migration, Integration and Social Cohesion in Europe), in a panel convened by IMISCOE's Ageing Migrants research cluster. The overarching theme of the conference was 'Mobility as the new paradigmatic perspective in the social sciences?' The question posed by this title was, and remains, apposite: the last decade has witnessed a 'mobilities turn' proposing major reorientations in how social scientists perceive and undertake research in a large range of fields. Yet from our early discussions for the conference panel, it transpired that the experiences of older people - and particularly older migrants - had been largely ignored in the mobilities literature. This special issue aims to address this lacuna.

Our introduction is structured in two parts. The first section gives an overview of the conceptual development of the 'new mobilities paradigm'. We describe how the mobilities turn in the social sciences has generated a rich conceptual and methodological modus operandi for scholars of population movements. However, recognising the validity of earlier critiques, we note that it is important not to overstate the novelty of the movements of people and things, nor to overlook fixity and friction, the less mobile and barriers to mobility. As we go on to argue, both of these caveats are of particular relevance when considering the utility of the mobilities perspective for the study of older migrants. Is this perspective useful when studying the experiences of older migrants whose mobility is not new, or who are less mobile today than in the past? And, in the other direction, what insights does research on older migrants offer to the conceptual and theoretical refinement of the mobilities paradigm? The second part introduces the papers in this special issue and relates them to the wider relevant literature.

\section{THE NEW MOBILITIES PARADIGM: WHAT PLACE FOR OLDER MIGRANTS?}

As noted, the last decade has witnessed a 'mobilities turn' in the social sciences, with particular resonance for the fields of study covered by this journal. The undeniable popularity of the 'mobilities' approach is due in part to the success its proponents have had in bringing together a large number of empirical domains and academic disciplines in the study of ongoing processes of globalisation, centred around "a fundamental geographical fact of life - moving” (Cresswell, 2011: 551). Thus the mobilities paradigm bridges the narrower focus of fields of study such as migration, tourism and transport, combining the geographical study of population movement at a wide variety of scales and temporalities, from international and intra-national migration flows to tourism and commuting. Furthermore, the mobilities paradigm looks at a variety of things that move, not just humans but also ideas and objects, and especially how humans and non-human elements move in tandem or in related ways (e.g. mobile 
technologies). Mobilities work also pays attention to the fixed infrastructure such as airports, border posts and container shipping terminals which channel mobility. In a review article, Mimi Sheller (2014) seeks to capture the core themes in the new mobilities paradigm:

“...the new transdisciplinary field of mobilities research encompasses research on the spatial mobility of humans, non-humans, and objects; the circulation of information, images, and capital; as well as the study of the physical means for movement such as infrastructures, vehicles, and software systems that enable travel and communication to take place. Thus it brings together some of the more purely 'social' concerns of sociology (inequality, power, hierarchies) with the 'spatial' concerns of geography (territory, borders, scale) and the 'cultural' concerns of anthropology or communication research (discourses, representations, schemas), while inflecting each with a relational ontology of the co-constitution of subjects, spaces, and meanings.” (Sheller, 2014: 791)

Delving further into the relevant literature, one comes across a variety of definitions of mobility. Urry (2007) distinguishes between five types of mobility: corporeal travel; physical movement of objects; imaginative travel enabled by media, photos, books, television; virtual travel facilitated by the internet; and communicative travel through various technologies such as messaging, letters, telephones, e-mails and so on.

One of the key points made by the new mobilities literature is the observation that access to mobility is profoundly influenced by disparities in power, or what Cresswell calls the “differentiated politics of mobility” (2011: 552). As Tesfahuney argues, “Differential mobility empowerments reflect structures and hierarchies of power and position by race, gender, age and class, ranging from the local to the global” (1998: 501). Glick Schiller and Salazar (2013) have coined the concept of 'regimes of mobility' to underline the power relations which govern access to mobility and migration. While the mobility of elites is facilitated and freely chosen, the mobility of lower skilled migrants may be strongly policed and constrained by state actors, while undocumented migrants may have mobility enforced upon them in order to escape detection by deportation authorities.

Methodological innovation is a further hallmark of research conducted in the new mobilities paradigm. The term 'mobile methods' refers to methodological approaches that "capture, perform, and even intervene in processes of movement as they happen” (Sheller, 2014: 801). Mobile ethnography implicates researchers in acts of mobility, as they travel, walk and follow their respondents. A particularly privileged site of observation are those 'places of in-between- 
ness' or 'transfer points' (Kesselring, 2006), such as airport terminals. Time-space diaries are a further means to record respondents' mobility and their different enactments in different locations over a certain period (Stjernborg, Wretstrand, \& Tesfahuney, 2015). Moving beyond physical mobilities, imaginative and virtual mobilities can be studied by using online resources and multimedia methods (Sheller \& Urry, 2006).

Given the rapid rise and disciplinary diffusion of the mobilities paradigm, it is hardly surprising that in reaction a number of critiques emerged to question this tendency. A first critique argued that the claim of novelty in the 'new' mobilities paradigm was exaggerated: mobilities have long been studied, moorings are equally important as mobility, and there is not a clear-cut paradigmatic change (Cresswell, 2010; Glick Schiller \& Salazar, 2013). Nonetheless, nuanced critiques have acknowledged that the mobilities perspective does bring together "a diverse array of forms of movement across scales ranging from the body [...] to the globe” (Cresswell, 2010: 18). The novelty of the mobilities approach lies in bringing together these diverse forms and scales for a "holistic understanding of mobilities" (Cresswell, 2010: 18).

A second critique argued that the mobilities literature neglected the barriers to mobility, what Cresswell terms 'friction' (Cresswell, 2010). When reading the early mobilities literature this critique appears mis-placed, since the key initial statements made a point of incorporating in their conceptual frameworks the opposites of physical movement - stillness, immobility, stopping, as well as virtual mobility mediated by new information and communication technologies, and imaginary forms of movement (Hannam et al., 2006; Urry, 2007). However, it has been acknowledged that subsequent empirical work has been overly focused on the archetypally mobile - business elites, young professionals, and so on, who have a lot of agency - and has left aside the less mobile (Hannam, 2011).

In summarising the development of the mobilities paradigm, and its principal critiques, we contend that the 'mobilities turn' in the social sciences has initiated a rich theoretical and methodological discussion for scholars of migration, but one must be careful neither to overstate the novelty of the movements of people and things, nor to overlook fixity and friction, the less mobile and barriers to mobility. This brings us to a further critical perspective which we wish here to draw attention to, namely the lack of attention to older people's experiences in the mobilities paradigm.

Ageing people have generally been sidelined in the new mobilities literature. A search of the journal Mobilities, which can be taken as broadly representative of the body of 'new mobilities' research, is instructive in this regard, with a clear preponderance of research on children's and young adults' mobilities. Since a special issue of Mobilities in 2009 (Barker et al., 2009) on 
new directions in children's mobility, there has been a proliferation of studies linking the conceptual frame of the mobilities paradigm with young people. By contrast, work on older adults drawing on the new mobilities literature was until recently non-existent in the journal's output. When older people have been considered it is as 'left-behind' kin and their relationships with more mobile younger relatives (Reynolds, 2011; Vathi \& King, 2011). However, in recent years a new interest in older people's mobilities has emerged, focussing particularly on the role of mobility in facilitating well-being in later life (Nordbakke \& Schwanen, 2014; Stjernborg et al., 2015).

Given the marginal position of older people in the mobilities perspective, it is not surprising that when it comes to older migrants we find even fewer references drawing on the new mobilities paradigm. Importantly, insofar as work on ageing migrants' mobilities is concerned, the few existing studies have tended to look at mobility as physical movement, focusing primarily on older 'lifestyle’ migrants (Benson, 2011; 2013; Green, 2015; Ono, 2015). As will be proposed below, novel avenues to explore in future research include imaginary and virtual mobilities (Ziegler \& Schwanen, 2011), which may be of particular relevance when discussing older people who have reduced physical mobility.

Conceptual refinements building upon the foundational texts of the mobilities paradigm are promising for gerontologists and others who work with older people. Urry’s classification was critiqued for prioritising physical and electronic flows over "movement in social, psychological, conceptual or imaginative spaces” (Frello, 2008). Ziegler and Schwanen (2011) apply Frello's approach and build on it to overcome the limitations of the instrumental definition of mobility equated to physical functioning which is highly pervasive in social gerontology. Against this view, they instead look at mobility "as the transgression of difference or distinction (...) expressed for instance as an open and inviting attitude towards people who are 'different' (in terms of age, gender and race/ ethnicity)” (Ziegler \& Schwanen, 2011: 762763). This disposition to connect with 'difference' in later life is of particular relevance to older migrants, given their prior experiences of migrating to a new culture or environment. Their wellbeing may also be boosted through physical mobility such as return visits to home places, and when these are no longer possible due to old age and illness, they can still engage in imagined mobilities through food, memories, photos, stories and letters that take them back in time and to geographically distant places.

A final issue to consider in this overview of the relevant literatures is the heterogeneity of older migrants. Research on older migrants has grown significantly since the turn of the century, much of it at the intersection between migration studies and gerontology. The main research 
themes have been return migration (Bolzman, Fibbi, \& Vial, 2006; Ciobanu \& Ramos, 2016; Hunter, 2011), care (Baldassar, Baldock, \& Wilding, 2007; Horn et al., 2016; Karl, Ramos, \& Kühn, 2017; Torres, Ågård, \& Milberg, 2016), international retirement migration (Gehring, 2016; King, Warnes, \& Williams, 2000), and increasingly transnationalism (Burholt, Dobbs, \& Victor, 2016; Horn \& Schweppe, 2016) and the use of ICT (Baldassar et al., 2016; Hunter, 2015). An important contribution was made by Warnes and colleagues (2004) who, without being exhaustive, underline that older migrants constitute a highly heterogeneous population. They distinguish between four categories of older migrants in the European context:

1. Amenity-seeking international retirement migrants: those who migrate at an advanced age from the North to the South of Europe (and increasingly further afield, to destinations such as South-East Asia or Central and South America). Individuals who engage in this type of migration may also be referred to as older 'lifestyle migrants'.

2. Older European international labour migrants and older non-European international labour migrants: those who have 'aged in place' following their arrival in Europe after WWII.

3. Linked to the previous category are return labour migrants. This refers to postWWII labour migrants who choose to spend their retirement in the country of origin.

4. Family-oriented international retirement migrants: those who migrate later in life to be closer to relatives who emigrated previously. Nedelcu (2009), in her study of Romanian older people who travel to Canada for shorter or longer periods to take care of their grandchildren, calls this group the "zero generation".

The six articles in this special issue bring together a variety of migration trajectories and mobility experiences in later life, corresponding to the above categories identified by Warnes and colleagues (2004). The paper which opens the special issue (Rallu, 2017) projects the population of foreign-born elders in France in the coming decade, drawing attention among other things to the influence of late-in-life returns and family-joining moves. The papers by Gehring and Botterill illuminate lifestyle or amenity-seeking mobilities, respectively focusing on Dutch migrants to Spain (Gehring, 2017) and British migrants to Thailand (Botterill, 2017). Older labour migrants, whether ageing 'in place' or pursuing more mobile 'bi-residence' lifestyles, feature in four of the articles, with papers respectively on Italians, Spaniards and Portuguese in Switzerland (Bolzman, Kaeser, \& Christe, 2017), Spaniards in the Netherlands (Gehring, 2017), Turks in Belgium (Buffel, 2017) and Pakistanis in the UK (Ali \& Suleman, 2017). The next section provides an overview of the papers. 


\section{OLDER MIGRANTS' (IM)MOBILITIES}

The contributions of the articles collected here respond to two guiding questions, as follows: (i) What added value does the new mobilities paradigm contribute to the study of older migrants? and (ii) Insofar as older migrants have not been a major focus in the mobilities literature, what added value does studying older migrants contribute to the mobilities paradigm?

Before elucidating these questions, it is important to seize the demographic dimensions of migrant ageing and late-in-life (im)mobility. The special issue opens with a paper by JeanLouis Rallu on population projections of older migrants in France, which was one of the first European countries to facilitate the arrival of labour migrants after World War II. France is therefore a country where the ageing of the migrant population is somewhat advanced, indicating likely future scenarios for other countries with more recent experiences of largescale immigration. Rallu's projections are pioneering in relation to France, and moreover at the international level constitute one of the few attempts to project older migrant populations thus far. His work draws attention to significant increases in the population of older migrants in France. His projections to 2028 show that the number of Moroccans and Turks aged over 65 in France will increase more than two-fold, and sub-Saharan Africans up to six-fold. Another important insight from Rallu's analysis is that age-structure varies according to origin and migration history, affected by pre- and post-independence migrations, economic booms and busts, and policy changes such as France’s ‘closed border’ policy after 1975. Furthermore, the population pyramids which Rallu presents in the article indicate some important differences by gender. For male migrants, post-retirement returns to countries of origin are observable, although these flows are small. There are also significant numbers of women migrating to France later in life, primarily in the context of late family reunifications. These demographic changes are likely to have important implications for service providers in the fields of health and elder care, especially in localities with significant migrant populations.

With a fuller understanding of the demographic dimensions of migrant ageing and late-in-life (im)mobilities, we are in a better position to interrogate the utility of the mobilities paradigm for older migrant populations. The gendered trends discerned by Rallu at the quantitative level are elaborated in the qualitative and mixed-method papers of the special issue. Taking into account gender is critical when it comes to analysing decisions about future mobility (Bolzman et al., 2006), especially the question of return to places of origin at retirement, which is a prominent theme in the literature on older migrants (Ciobanu \& Ramos, 2016). Freed from the 
sedentary constraint of participation in the receiving country's labour market thanks to pensions which are largely exportable (Hunter, 2011), many older migrants have the financial resources to relocate to pursue their retirement projects if they so wish. A minority do return definitively, but as quantitative surveys from France and Switzerland show, most older migrants envisage a bi-residence strategy, spending significant periods of the year in countries of origin but maintaining primary residence in the receiving country where adult children and grandchildren are settled (Attias-Donfut, Tessier, \& Wolff, 2005; Bolzman et al., 2006). Furthermore, as several studies have shown, willingness to return is not always shared equally in firstgeneration migrant couples. Generally, male partners are more willing to return permanently than female partners (Balkır \& Böcker, 2010; Bolzman et al., 2006).

The two papers respectively by Anoeshka Gehring and by Claudio Bolzman, Laure Kaeser and Etienne Christe bring to light new insights into these late-in-life transnational mobility practices. Drawing on findings from a mixed-method (survey- and interview-based) study of Spanish, Portuguese and Italian older people living in Switzerland, Bolzman and colleagues make the important point that regardless of whether older migrants decide to settle in Switzerland or their home countries this does not imply that their transnational mobility ceases. Those settled in Switzerland make regular trips to their places of origin, while those who returned to Spain or Italy visit their children and grandchildren who live in Switzerland. The duration and objectives of mobility are very much related to family configurations in both countries, as well as to health and housing situations. While the principle of free movement within the European Union facilitates such mobility, this freedom is not absolute: Bolzman and colleagues stress that state regulations continue to be a structural constraint, notably to retain permanent residence status and maintain eligibility to non-contributory welfare benefits. Finally, their data confirm previously observed differences with regard to return intentions, with men being likelier to return. The authors explain this by arguing that the men's social status is more dependent on employment than their spouses, and they are therefore more concerned about suffering a 'double absence', i.e., "not being recognised as part of Swiss society and being physically far from their home country” (Bolzman et al., 2017).

The third paper in this volume, by Anoeshka Gehring, also interrogates the practice of biresidence. Methodologically Gehring's approach is innovative as she compares retired labour migrants and amenity-seeking migrants moving in the same geographic space: both groups spent their working lives in one country (the Netherlands) and move or return to another country (Spain). She gives particular attention to the legal rules imposed by the EU and the Spanish and Dutch states which regulate the mobility of Dutch and Spanish retirees. Drawing 
on the mobilities literature, Gehring introduces the concept of 'legal gates' to describe the "everyday rules and regulations at different local, national, and supranational levels which facilitate or impede human mobility between one jurisdiction and another” (Gehring, 2017). Importantly, such gates may also enforce mobility on those who would otherwise prefer to remain in situ. Going beyond a structural description of these 'mobility regimes' (Glick Schiller \& Salazar, 2013), Gehring proceeds to a more agent-centred analysis of how older migrants deal with legal gates in practice. She finds that her financially better-off respondents are less constrained by legal gates, whereas the less privileged face limits to their mobility because of their reliance on welfare support which is conditional on observing minimum periods of residence in one or other country.

This question of privilege and precarity in late-in-life migration is picked up in the fourth contribution here. Kate Botterill's article on British retirement migrants in Thailand challenges the assumption made in the lifestyle migration literature that such migrants are amongst the most prosperous and privileged of older people. Her findings show that Brits in Thailand experience financial insecurity due to the UK government's policy of 'freezing' state pensions if exported to countries which have not signed bilateral social security agreements with the UK. Currency exchange rate fluctuations may also negatively affect the financial security of older Brits abroad. The high cost of healthcare in Thailand, and the insurance premiums levied on foreigners, are also a cause of anxiety. UK government policies have major consequences for those who have to return to Britain due to financial or health difficulties: access to healthcare, social housing and other welfare services in the UK is conditional upon having a 'local connection' to a given local authority and is subject to meeting a test of 'habitual residence'.

Local connections also become important in the case of the ageing Turkish migrants in Brussels studied by Tine Buffel. Her article notes high levels of attachment to, and mobility between, places marked as transnational (e.g. certain neighbourhoods in Brussels linked to certain places of origin in Turkey). However this is coupled paradoxically with greater detachment and lower levels of interaction with non-migrant populations both in Belgium and Turkey. In other words, the mobilities of older migrants in this case are highly localised, both in receiving and sending destinations. At a micro level, mobility within migrant neighbourhoods in Brussels can be highly constrained along gender lines: both male and female respondents referred to certain areas as 'male spaces', and these are places which older Turkish women are under strong normative pressure not to enter. Buffel argues that the new mobilities paradigm permits a more 
relational understanding of home and host places, building on theories of multiple place attachment to produce a valuable contribution to the social gerontology literature.

As is described in a number of the articles, different compensatory mechanisms are available allowing older migrants to be 'active' and to communicate across large distances. An excellent example of this is found in the article by Nazia Ali and Rukeya Suleman, which concludes this special issue. As noted in the review above, the new mobilities paradigm considers the mobility not only of people but also ideas and material objects, and especially how different types of objects move in tandem or in related ways. Ali and Suleman focus on the mobilities of older first-generation Pakistani women migrants to the United Kingdom and the material culture of gift-giving which moves with them to (and from) the ancestral homeland. Gift-giving engenders embodied mobility at a variety of times and scales: in and between different hubs of Pakistani settlement in the UK in order to coordinate gift-giving prior to departure, during the return visit to Pakistan, and finally after returning to the UK in order to distribute reciprocated gifts. Importantly, older Pakistani migrants who are too frail to travel still engage in the culture of gift-giving as their material goods are taken by their friends and relatives to kin in Pakistan. These women, on the 'slow tracks' of social life (Hannam et al., 2006), are able to compensate for their physical immobility and protect their social status in the gift-giving relationship through vicarious and imagined connections, meetings and journeys.

\section{FUTURE PROSPECTS: MOVING ON}

The movement of people is a core concern of population geographers and the last decade has witnessed a 'mobilities turn' in the social sciences. Of course another core concern in population geography is ageing. The mobilities literature has given much attention to younger people who move, but thus far has largely ignored people who migrate in later life, or whose previous migrations significantly shape their present experiences of ageing. The articles collected in this special issue have addressed that lacuna. More specifically, the ambition of the special issue has been to respond to two questions. What added value does the new mobilities paradigm contribute to the study of older migrants? And conversely, what added value does studying older migrants contribute to the mobilities paradigm?

In response to the latter question, our first observation is that older migrants merit more attention from scholars engaging with the mobilities paradigm. Older migrants constitute a population of growing numerical importance in countries which imported migrant labour after WWII, as Rallu's demographic projections here show. Similarly, the numbers involved in other forms of late-in-life migration, such as amenity or lifestyle migration, appear to be growing. 
The upward trend in the number of pensions paid abroad is one indicator of this (Böcker and Hunter, 2017).

In recent years scholars from different disciplines have begun to grasp the rich potential that research with older migrants offers for theoretical development and social practice (e.g. Gunaratnam, 2013; Torres, 2015). As the papers assembled here show, there is similar scope for scholars working within the new mobilities paradigm to fruitfully engage with these demographic evolutions. One key issue which several contributions in this issue underscore is the influence on older people's mobility of administrative rules and laws, be that in the countries where they previously lived and worked or in the countries where they now spend their retirement. These ‘legal gates’ (Gehring, 2017) are more salient for older people in general given that they have greater recourse to social security and healthcare systems, and particularly so for older migrants since such welfare systems are predicated on the assumption of a largely static and bounded population (Ackers \& Dwyer, 2004).

On the question of what added value the new mobilities paradigm brings to the burgeoning scholarship on older migrants, we would underline three insights from the papers collected here. As noted in the review above, one advantage of the new mobilities paradigm is that it offers potential for studying mobilities at different scales. Scholars of migration have tended to prioritise certain mobilities which for most people continue to be quite rare, i.e. the crossing of administrative, and especially national, borders. There has been less attention from migration scholars to other forms of mobility at lesser scales which occur after significant (i.e. bordercrossing) migration episodes. The capacity for mobility after migration (e.g. at more local scales; return visits; or bi-residence strategies) is an important but overlooked factor in how older people achieve better quality of life (Benson, 2011; Schwanen \& Ziegler, 2011).

Furthermore, by focusing not only on physical mobility of persons but also the mobility of things and virtual and imaginary mobilities, the mobilities paradigm may be of special relevance to older people's experiences, as the contribution by Ali and Suleman in this issue shows. These forms of mobility, often facilitated or enhanced by new technologies, may provide compensatory mechanisms when physical movement becomes difficult and can contribute to reducing the loneliness which some older migrants suffer (Fokkema \& Naderi, 2013).

Lastly, the new mobilities paradigm aims to bridge the 'antagonistic' categories of mobility and stillness (Cresswell, 2010; 2012). Usually, the category of 'mobility' is defined in opposition to that of 'immobility'. Glick Schiller \& Salazar (2013) argue that it is important to overcome this reductive binary thinking and conceive of both movement and stasis as integral and 
interconnected aspects of the human condition. The contributions in this special issue show that this is especially pertinent in the context of old age, when people eventually become less mobile physically yet are able to compensate for this by undertaking other forms of mobility or by drawing upon resources gained through previous experiences of mobility. Thus it is important to have a mobile gaze on immobile lives. 


\section{Bibliography}

Ackers, L., \& Dwyer, P. (2004). Fixed laws, fluid lives: the citizenship status of post-retirement migrants in the European Union. Ageing \& Society, 24(3), 451-475. DOI: 10.1017/S0144686X0300165.

Ali, N., \& Suleman, R. (2017). Mobilities of older Pakistani female migrants and material culture: a multi-generational perspective on gift-giving. Population, Space and Place. DOI.org/10.1002/psp.2067.

Attias-Donfut, C., Tessier, P., \& Wolff, F. C. (2005). Les immigrés au temps de la retraite. Retraite et société, 44(1), 11-47.

Baldassar, L., Baldock, C., \& Wilding, R. (2007). Families Caring Across Borders: Migration, Aging and Transnational Caregiving. London: Palgrave MacMillan.

Baldassar, L., Nedelcu, M., Merla, L., \& Wilding, R. (2016). Migration and ICTs: 'being together' and 'co-presence' in transnational family life. Special Issue, Global Networks, 16(2).

Balkır, C., \& Böcker, A. (2012). Migration in later life: residence, social security and citizenship strategies of Turkish return migrants and Dutch retirement migrants in Turkey (Nijmegen migration law working papers series - external research report). Nijmegen: Radboud University Nijmegen. (p. 93)

Barker, J., Kraftl, P., Horton, J., \& Tucker, F. (2009). The road less travelled - new directions in children's and young people's mobility. Mobilities, 4(1), 1-10. DOI: 10.1080/17450100802657939.

Benson, M. (2011). The movement beyond (lifestyle) migration: mobile practices and the constitution of a better way of life. Mobilities, 6(2), 221-235. DOI: 10.1080/17450101.2011.552901.

Benson, M. (2013). Postcoloniality and privilege in new lifestyle flows: the case of North Americans in Panama. Mobilities, 8(3), 313-330. DOI: 10.1080/17450101.2013.810403.

Böcker, A., \& Hunter, A. (2017). Legislating for transnational ageing: a challenge to the logics of the welfare state. European Journal of Ageing.

Bolzman, C., Fibbi, R., \& Vial, M. (2006). What to do after retirement? Elderly migrants and the question of return. Journal of Ethnic and Migration Studies, 32(8), 1359-1375. DOI: 10.1080/13691830600928748.

Bolzman, C., Kaeser, L., \& Christe, E. (2017). Transnational mobilities as a way of life among older migrants from Southern Europe. Population, Space and Place. DOI.org/10.1002/psp.2016. 
Botterill, K. (2017). Discordant lifestyle mobilities in East Asia: privilege and precarity of British retirement in Thailand. Population, Space and Place. DOI.org/10.1002/psp.2011. Buffel, T. (2017). Ageing migrants and the creation of home: mobility and the maintenance of transnational ties. Population, Space and Place. DOI.org/10.1002/psp.1994.

Burholt, V., Dobbs, C., \& Victor, C. R. (2016). Transnational relationships and cultural identity of older migrants. GeroPsych - the Journal of Gerontopsychology and Geriatric Psychiatry, 29(2), 57-69. DOI. 10.1024/1662-9647/a000143.

Ciobanu, R. O., \& Ramos, A. C. (2016). Is there a way back? An overview of the literature on retirement return migration. In Karl, U., \& Torres, S. (Eds.) Ageing in Contexts of Migration (pp. 96-107). London: Routledge.

Cresswell, T. (2010). Towards a politics of mobility. Environment and Planning D: Society and Space, 28(1), 17-31. DOI: 10.1068/d11407.

Cresswell, T. (2011). Mobilities I: Catching up. Progress in Human Geography, 35(4), 550558. DOI: 10.1177/0309132510383348.

Cresswell, T. (2012). Mobilities II: Still. Progress in Human Geography, 36(5), 645-653. DOI: 10.1177/0309132511423349.

Fokkema, T., \& Naderi, R. (2013). Differences in late-life loneliness: a comparison between Turkish and native-born older adults in Germany. European Journal of Ageing, 10(4), 289-300. DOI: 10.1007/s10433-013-0267-7.

Frello, B. (2008). Towards a discursive analytics of movement: on the making and unmaking of movement as an object of knowledge. Mobilities, 3(1), 25-50. DOI: 10.1080/17450100701797299.

Gehring, A. (2016). Dutch retirement migration to Spain and Turkey: seeking access to healthcare across borders. Transnational Social Review - A Social Work, 6(3), 326-343. DOI: $10.1080 / 21931674.2016 .1180870$.

Gehring, A. (2017). Pensioners on the move: a 'legal gate’ perspective on retirement migration to Spain. Population, Space and Place. DOI.org/10.1002/psp.2007.

Glick Schiller, N., \& Salazar, N. B. (2013). Regimes of mobility across the globe. Journal of Ethnic and Migration Studies, 39(2), 183-200. DOI: 10.1080/1369183X.2013.723253.

Green, P. (2015). Mobility regimes in practice: later-life westerners and visa runs in SouthEast Asia. Mobilities, 10(5), 748-763. DOI: 10.1080/17450101.2014.927203.

Gunaratnam, Y. (2013). Death and the Migrant: Bodies, Borders and Care. London: Bloomsbury. 
Hannam, K., Sheller, M., \& Urry, J. (2006). Editorial: Mobilities, immobilities and moorings. Mobilities, 1(1), 1-22. DOI: 10.1080/17450100500489189.

Hannam, K. (2011). Mobilities and social exclusion: towards a research agenda. In McCabe, S., Minnaert, L., \& Diekmann, A. (Eds.) Social Tourism in Europe: Theory and Practice (pp. 92-102). Bristol: Channel View Publications.

Horn, V., \& Schweppe, C. (Eds.) (2016). Transnational Aging: Current Insights and Future Challenges. London/New York: Routledge.

Horn, V., Schweppe, C., Bender, D., \& Hollstein, T. (2016). 'Moving (for) elder care abroad': the fragile promises of old-age care facilities for elderly Germans in Thailand. In Horn, V., \& Schweppe, C. (Eds.) Transnational Aging: Current Insights and Future Challenges (pp. 163-177). London/New York: Routledge.

Hunter, A. (2011). Theory and practice of return migration at retirement: the case of migrant worker hostel residents in France. Population, Space and Place, 17(2), 179-192. DOI: 10.1002/psp.610.

Hunter, A. (2015). Empowering or impeding return migration? ICT, mobile phones, and older migrants' communications with home. Global Networks, 15(4), 485-502. DOI: 10.1111/glob.12091.

Karl, U., Ramos, A. C., \& Kühn, B. (2017). Older migrants in Luxembourg - care preferences for old age between family and professional services. Journal of Ethnic and Migration Studies, 43(2), 270-286. DOI: 10.1080/1369183X.2016.1238909.

Kesselring, S. (2006). Pioneering mobilities: new patterns of movement and motility in a mobile world. Environment and Planning A, 38, 269-279. DOI: 10.1068/a37279.

King, R., Warnes, T., \& Williams, A. (2000). Sunset Lives. British Retirement Migration to the Mediterranean. Oxford: Berg Publishers.

Nedelcu, M. (2009). La génération zéro: du sédentaire à l'acteur circulant. Effets de mobilité sur la génération des parents des migrants roumains hautement qualifiés à Toronto à l'ère du numérique. In Cortes, G., \& Faret, L. (Eds.) Les circulations transnationales. Lire les turbulences migratoires contemporaines (pp. 187-198). Paris: Armand Colin.

Nordbakke, S., \& Schwanen, T. (2014). Well-being and mobility: a theoretical framework and literature review focusing on older people. Mobilities, 9(1), 104-129. DOI: 10.1080/17450101.2013.784542.

Ono, M. (2015). Commoditization of lifestyle migration: Japanese retirees in Malaysia. Mobilities, 10(4), 609-627. DOI: 10.1080/17450101.2014.913868.

Rallu, J.-L. (2017). Projections of older immigrants in France, 2008-2028. Population, Space 
and Place. DOI.org/10.1002/psp.2012.

Reynolds, T. (2011). Caribbean second-generation return migration: transnational family relationships with 'left-behind' kin in Britain. Mobilities, 6(4), 535-551. DOI.org/10.1080/17450101.2011.603946.

Schwanen, T., \& Ziegler, F. (2011). Wellbeing, independence and mobility: an introduction. Ageing \& Society, 31(5), 719-733. DOI: 10.1017/S0144686X10001467.

Sheller, M. (2014). The new mobilities paradigm for a live sociology. Current Sociology Review, 62(6), 789-811. DOI: 10.1177/0011392114533211.

Sheller, M., \& Urry, J. (2006). The new mobilities paradigm. Environment and Planning A, 38, 207-226. DOI: 10.1068/a37268.

Stjernborg, V., Wretstrand, A., \& Tesfahuney, M. (2015). Everyday life mobilities of older persons - a case study of ageing in a suburban landscape in Sweden. Mobilities, 10(3), 383-401. DOI: 10.1080/17450101.2013.874836.

Tesfahuney, M. (1998). Mobility, racism and geopolitics. Political Geography, 17(5), 499515.

Torres, S. (2015). Expanding the gerontological imagination on ethnicity: conceptual and theoretical perspectives. Ageing \& Society, 35(5), 935-960. DOI: 10.1017/S0144686X14001330.

Torres, S., Ågård, P., \& Milberg, A. (2016). The 'other' in end-of-life care: care providers on patients with migrant backgrounds. Journal of Intercultural Studies, 37(2), 103-117. DOI: 10.1080/07256868.2016.1141756.

Urry, J. (2007). Mobilities. Cambridge: Polity Press.

Vathi, Z., \& King, R. (2011). Return visits of the young Albanian second generation in Europe: contrasting themes and comparative host-country perspectives. Mobilities, 6 (4), 503518. DOI: 10.1080/17450101.2011.603944.

Warnes, A. M., Friedrich, K., Kellaher, L., \& Torres, S. (2004). The diversity and welfare of older migrants in Europe. Ageing \& Society, 24, 307-326. DOI: 10.1017/S0144686X04002296.

Ziegler, F., \& Schwanen, T. (2011). 'I like to go out to be energised by different people': an exploratory analysis of mobility and wellbeing in later life. Ageing \& Society, 31(5), 758781. DOI: 10.1017/S0144686X10000498.

\section{Acknowledgements:}


We are very grateful to the IMISCOE Network for facilitating our session on older migrants and (im)mobilities at its Annual Conference in 2012, and for funding a follow-up workshop in March 2013 at the New University of Lisbon. This special issue is dedicated firstly to the memory of Graeme Hugo (1946-2015), Professor of Geography at the University of Adelaide, whose contribution to the Lisbon workshop inspired us to pursue a publication on this topic and whose advice was invaluable in framing the special issue. Secondly, we honour our colleague Etienne Christe (1950-2013), who co-authored one of the articles in the special issue. We would like to thank all the peer reviewers for their time and thorough comments.

Ruxandra Oana Ciobanu's work was funded by the People Programme (Marie Curie Actions) of the European Union's Seventh Framework Programme (FP7/2007-2013), [REA grant agreement no 328518]. 